\title{
Numerical Simulation of Concrete Degradation due to Chloride-Induced Reinforcement Corrosion
}

\author{
Olawale Olatunde Ayinde ${ }^{1, a}$, Xiao-Bao Zuo ${ }^{2, b}$ and Guang-Ji Yin ${ }^{3, c}$ \\ ${ }^{1}$ Nanjing University of Science \& Technology, Nanjing 210094, China \\ ${ }^{2}$ Nanjing University of Science \& Technology, Nanjing 210094, China \\ ${ }^{3}$ Nanjing University of Science \& Technology, Nanjing 210094, China

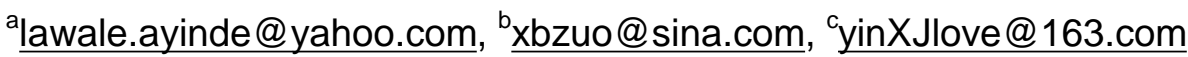

\section{Keywords: concrete, reinforcements, Abaqus, corrosion, cracking, XFEM}

Abstract. Concrete structures built in marine environment are susceptible to attack by chemicals such as chloride which diffuses into concrete structures and attack the reinforcements embedded in reinforced structures and break down the reinforcement protective layer. This paper presents the use of Abaqus Finite Element Analysis software in Analyzing the processes involved in concrete structure degradation from chloride diffusion to concrete cracking. Mass diffusion, Faraday's law and the Extended Finite Element Method (XFEM) were used to simulate chloride diffusion, mass loss from steel corrosion and corrosion product expansion and concrete cover cracking simultaneously, while the pressure due to the tensile stress generated by corrosion product was idealized as radial displacements. Obtained results show an increasing chloride concentration with time, but reduction with depth of penetration, while an obvious crack pattern was obtained.

\section{Introduction}

Corrosion of steel reinforcement embedded in concrete is identified as one of the major causes of structural deterioration of reinforced concrete members such as bridge decks, piers and other structures [1] because of the neutralization of the protective film around the steel reinforcement, which increases the vulnerability of steel reinforcements to corrosive agents. Chloride-induced corrosion begins when the concentration of chloride at the steel reinforcement reaches chloride threshold value, thereby destroying the protective layer; resulting into loss of the reinforcement cross-sectional area, gradual deterioration of the bond between concrete and steel reinforcement and cracking due to the expansion of rust products formed. The area around the rebar is dominated by tensile stress, produced by corrosion products, which leads to crack formation due to the expansive nature of the corrosion product in concrete cover, and eventually result to spalling of the concrete cover. This paper focuses on the implementation of the Finite Element method in simulating the processes involved in concrete degradation due to corrosion.

\section{Concrete degradation}

Concrete degradation involves processes such as chloride diffusion, corrosion and cracking of the concrete. Chloride diffusion is highly nonlinear and strongly coupled with other diffusive parameters such as temperature and relative humidity. Diffusion, which is the movement of chloride ions through saturated concrete due to a chloride concentration gradient, is usually characterized by Fick's second law, given by [2] as

$$
\mathrm{C}_{(\mathrm{x}, \mathrm{t})}=\mathrm{C}_{0}\left(1-\operatorname{erf}\left[\frac{\mathrm{x}}{2 \sqrt{\mathrm{D}_{\mathrm{ac}} \mathrm{t}}}\right]\right) \text {. }
$$

$\mathrm{C}_{(\mathrm{x}, \mathrm{t})}$ represents the chloride concentration $\left(\mathrm{kg} / \mathrm{m}^{3}\right)$ at $\mathrm{x}$ depth of penetration at time, $\mathrm{t}$ (years), $\mathrm{C}_{0}$ is the constant surface chloride concentration, and $D_{a c}$ is the apparent diffusion constant $\left(\mathrm{m}^{2} / \mathrm{s}\right)$.

The presence of chloride ions up to threshold around the reinforcement destroys the protective layer, cause corrosion initiation in the reinforcement, and produce corrosion products which accumulates 
at the concrete-steel interface transition zone (ITZ). Corrosion products formed initially fill up pores at the concrete-steel interface before exerting any internal pressure on the concrete cover $[3,4]$. When the total amount of corrosion product generated exceeds the amount needed to fill the pores, it creates stress in the concrete cover, by generating expansive pressure on the concrete. The expansive nature of corrosion products is generally modelled by uniform or non-uniform pressure and radial displacements [5,6], while a thermal analogy has also been used by [3]. A linear relationship between radial corrosion pressure $\mathrm{P}_{\text {corr }}$ and concrete displacement $\delta_{c}$ is given by [7] as

$$
\delta_{\mathrm{c}}=\mathrm{kP}_{\text {corr }} \text {. }
$$

where the hole flexibility, $\mathrm{k}$ is obtained from using $\delta_{0}=12.5 \mu \mathrm{m}$. The pressure exerted by corrosion products (which causes damage in the concrete) is obtained from [7]

$$
\mathrm{P}_{\text {corr }}=\frac{2 \mathrm{M}_{\text {loss }} \mathrm{E}_{\text {ef }}\left[\left(1 / 0.622 \rho_{\mathrm{r}}\right)-\left(1 / \rho_{\mathrm{s}}\right)\right]}{\pi \mathrm{D}(1+v+\psi)\left(\mathrm{D}+2 \delta_{0}\right)}-\frac{2 \delta_{0} \mathrm{E}_{\mathrm{ef}}}{(1+v+\psi)\left(\mathrm{D}+2 \delta_{0}\right)} \text {. }
$$

where negative values of $\mathrm{P}_{\text {corr }}$ denotes the duration in which the corrosion products fill the porous zone around the reinforcement. Damage in corroded reinforced concrete is usually manifested in form of cover cracking, due to the expansion of corrosion products around reinforcement. Crack initiation is defined based on the Rankine criterion, according to which a crack forms in the direction normal to the maximum principal tensile stress, when this stress exceeds the tensile strength of concrete [3]. A numerical simulation is presented for these steps.

\section{Numerical simulation}

An initially chloride-free cylindrical concrete sample is modeled and solved in the Mass Diffusion algorithm in Abaqus with boundary conditions of constant surface chloride content of $3.5 \mathrm{~kg} / \mathrm{m}^{3}$ and annually varying ambient temperature $\mathrm{T}_{\mathrm{amb}}=288.9+11.15 \sin (2 \pi \mathrm{t})$, using a solubility coefficient of unity. Fick's law diffusion algorithm was implemented with the transient analysis conducted for an exposure time of 100 years. The internal pressure due to reinforcement corrosion, is applied as a uniform radial displacement at the concrete-steel interface as presented by $[1,6]$.

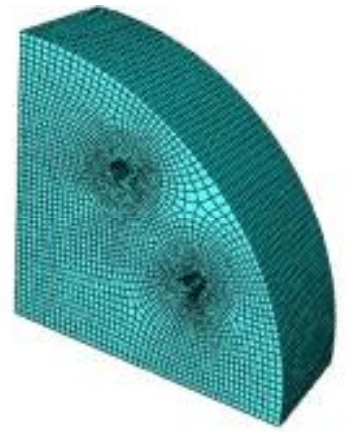

Fig. 1 Finite Element Mesh pattern.

\section{Result and Discussions}

Results from the diffusion analysis show that the constant surface concentration gradually decrease with depth of chloride penetration into the concrete, while chloride concentration at the rebar surface increases with time, as seen in Figs. (2) and (3) respectively. A chloride threshold value of $1.75 \mathrm{~kg} / \mathrm{m}^{3}$ ( $0.5 \%$ by wt. of cement) was obtained after 15 years of chloride diffusion, indicating corrosion initiation.

The corrosion rate, $\mathrm{i}_{\mathrm{corr}}$, which is an important parameter in determining the mass loss due to corrosion was obtained and the result, given in Fig. 4, show little fluctuation in the value of $\mathrm{i}_{\text {corr }}$, 
with corrosion time, which may be caused by the periodic variation of temperature. With a mean value of $0.7 \mu \mathrm{A} / \mathrm{cm}^{2}$ obtained for the dynamic corrosion rate, a moderate corrosion rate is indicated [8]. The initial high rate indicates a time of rapid corrosion which steadies out and became almost stable as the time after corrosion increases. Furthermore, the mass loss obtained, shows a linear relationship with corrosion time as seen in Fig. 5. With corrosion pressure obtained using Eq. 3, the radial displacements were obtained with Eq. 2. The displacements obtained however appeared big as noted by [9], that the radial displacement method leads to overestimation of the radial displacement. Cracks were already formed at lower values of applied radial displacements, however, the obtained radial displacement also gave good cracking pattern.

Using a smeared cracking approach and the Extended Finite Element Method (XFEM) in Abaqus, results show that the main vertical cracks initiate in the concrete and then propagate with increasing length and width, see Fig. (6). Other radial cracks inclined at $45^{\circ}$ or $90^{\circ}$ to the main crack, also propagate, in agreement with the observations of [3,5]. Crushing due to compression was noticed in the concrete elements closely located around the steel bar, which is consistent with field observations stated in [4], with an obvious crack growth indicating a link between cracks from two closely spaced reinforcements. With increase in the radial expansion around the bar, cracks occur first on the internal surface of the concrete cover and always at the location of the maximum Pressure. A delamination layer is observed in the concrete due to the connection of cracks from the two bar locations, as seen in Fig. 7. This makes the structure unstable at higher radial displacement. A linear relationship is observed between the crack width and the amount of corrosion which agrees well with [10] and is presented in Fig. 8.

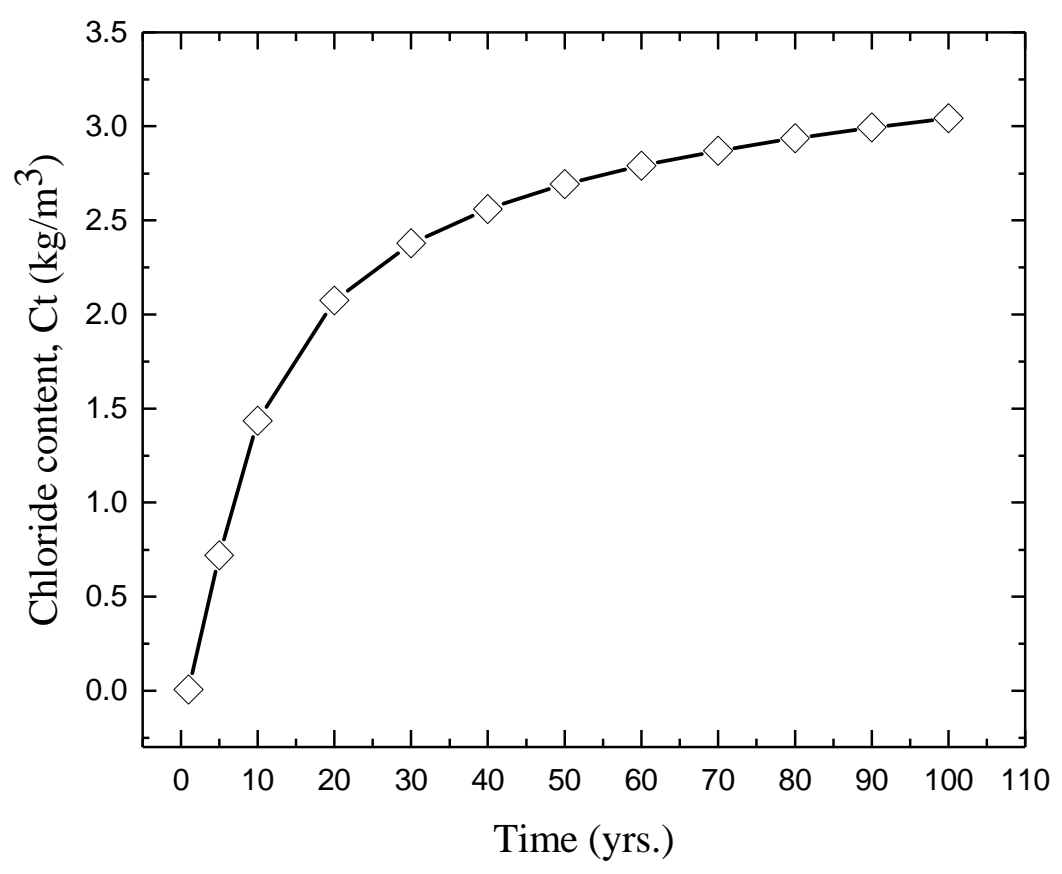

Fig. 2 Chloride distribution with years 


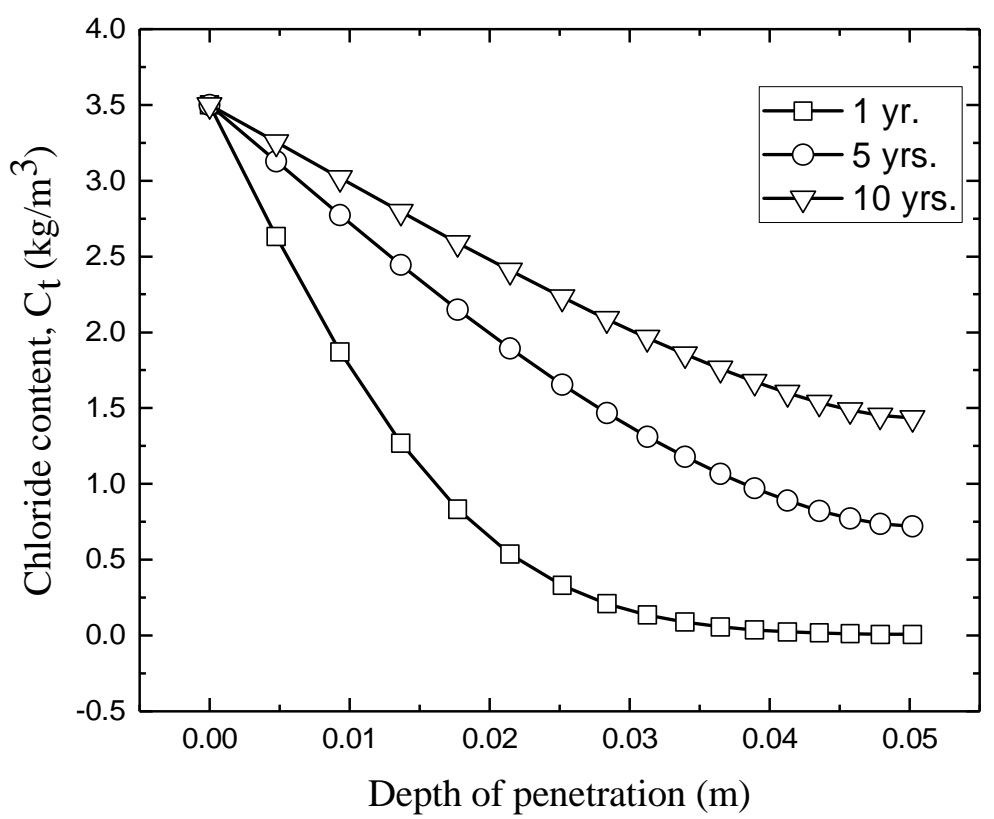

Fig. 3 Chloride distribution with depth of penetration

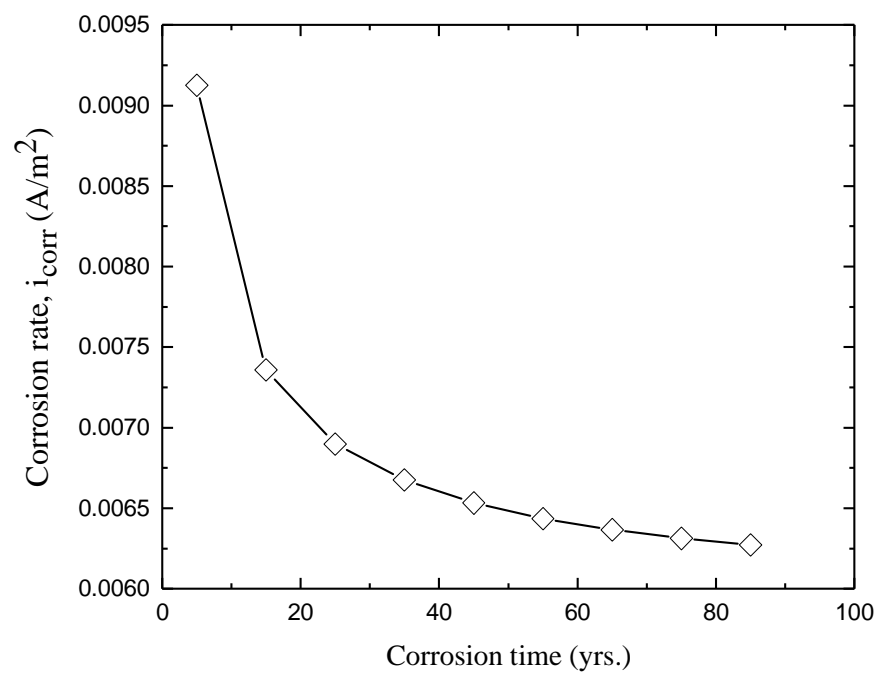

Fig. 4 Corrosion rate with corrosion time. 


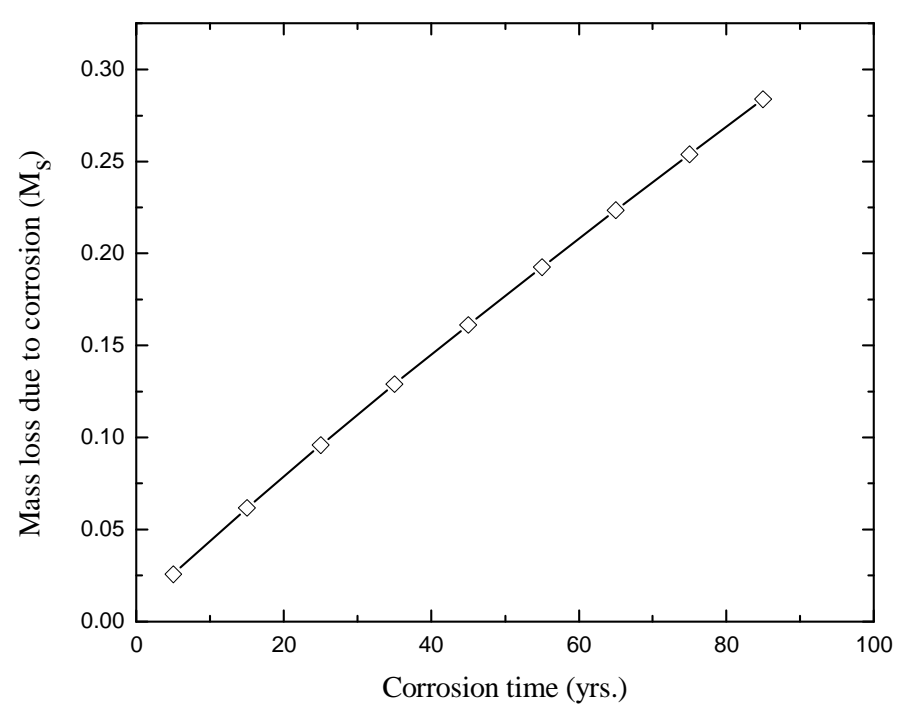

Fig. 5 Mass loss of the steel with corrosion time.

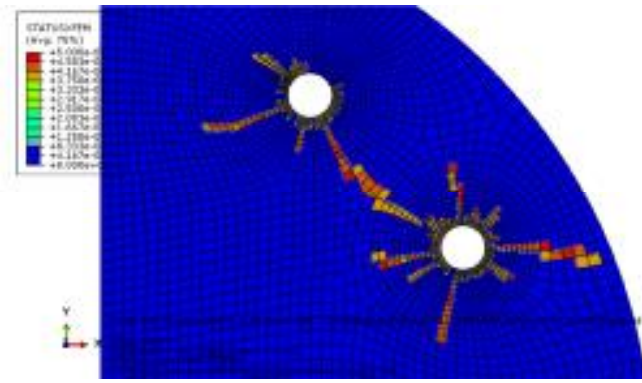

Fig. 6 Typical stress distribution and crack pattern obtained from the analysis.
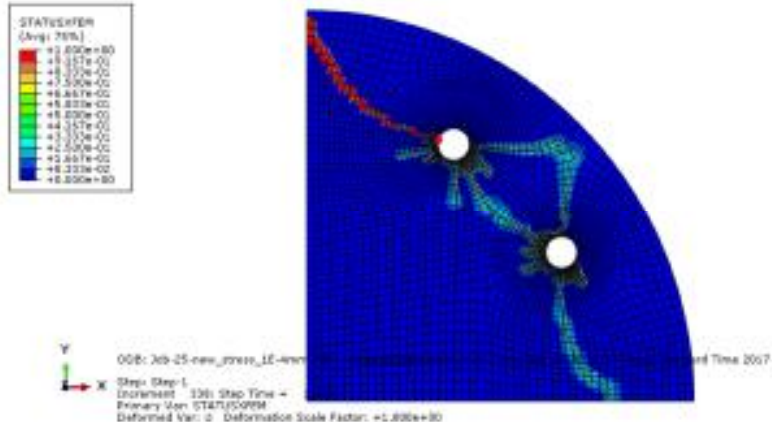

Fig. 7 Cracking and delamination pattern 


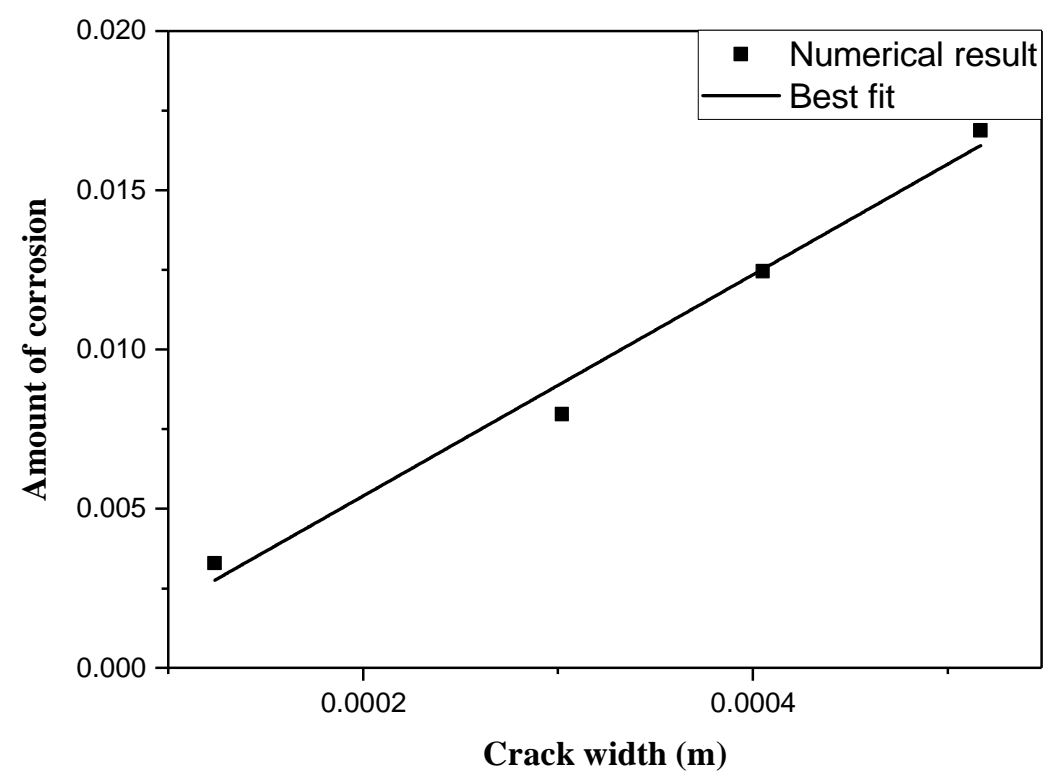

Fig. 8 Amount of corrosion against the crack width

\section{Summary}

This paper uses the Finite Element Method to simulate concrete durability degradation processes from chloride penetration to reinforcement rust expansion and then concrete cover cracking.

\section{Acknowledgment}

This study was financially supported by National Science Foundation of China (51378262, 51778297).

\section{References}

[1] K. Vu, M.G. Stewart and J. Mullard: Corrosion-induced cracking: Experimental data and predictive models: ACI Struct. J Vol. 102 (2005), p. 719-726.

[2] R.E. Weyers, B.D. Prowell, M.M. Sprinkel and M. Vorster: Concrete Bridge Protection and Rehabilitation: Chemical and Physical Techniques, Technical Report, Virginia Polytechnic Institute and State University, Blacksburg, Virginia. (1994).

[3] D.V. Val, L. Chernin and M.G. Stewart: Experimental and Numerical Investigation of Corrosion-Induced Cover Cracking in Reinforced Concrete Structures: J. Struct. Eng. Vol. 135 (2009), p. 376-385.

[4] D. Chen and S. Mahadevan: Chloride-induced reinforcement corrosion and concrete cracking simulation: Cem. Concr. Compos. Vol. 30 (2008), p. 227-238.

[5] P. Xiao, N. Yi, G. Li and L. Wang: Finite Element Analysis of Expansive Behavior due to reinforcement corrosion in RC structure. Procedia Engineering. Vol. 12 (2011), p. 117-126.

[6] T. El-Maaddawy and K. Soudki: A model for prediction of time from corrosion initiation to corrosion cracking: Cem. Concr. Compos. Vol. 29 (2007), p. 168-175.

[7] Y.G. Du, A.H.C. Chan and L.A. Clark: Finite Element analysis of the effects of radial expansion of corroded reinforcement: Comput. Struct. Vol. 84 (2006), p. 917-929. 
[8] S.J. Pantazopoulou and K.D. Papoulia: Modeling cover-cracking due to reinforcement corrosion in RC structures: J Eng. Mech. Vol. 127 (2001), p. 342-351.

[9] L. Chernin and D.V. Val: Prediction of corrosion-induced cover cracking in reinforced concrete structures. Constr. Build Mater. Vol. 25 (2011), p. 1854-1869.

[10] C. Andrade, C. Alonso, F.J. Molina: Cover cracking as a function of bar corrosion: Part 1Experimental test: Mater Struct. Vol. 26 (1993), p. 453-464. 